\title{
Effects of isentropic efficiencies on the performance of combined cycle power plants
}

\author{
Thamir K. Ibrahim ${ }^{1,2 *}$ and M. M. Rahman ${ }^{1,3}$ \\ ${ }^{1}$ Faculty of Mechanical Engineering, Universiti Malaysia Pahang, \\ 26600 Pekan, Pahang, Malaysia. \\ Email: thamirmathcad@yahoo.com; thamir@ump.edu.my; \\ ${ }^{2}$ Mechanical Engineering Departments, College of Engineering, \\ University of Tikrit, Tikrit, Iraq \\ ${ }^{3}$ Automotive Engineering Centre, Universiti Malaysia Pahang, \\ 26600 Pekan, Pahang, Malaysia.
}

\begin{abstract}
This study deals with modelling and performance enhancements of a combined cycle power plant. Several configurations of CCGT power plants are proposed by thermal analysis. The integrated model and simulation code for exploiting the performance of the CCGT power plant is developed utilizing MATLAB code. A different strategy for the CCGT power plant's operational modelling is suggested for power plant operation, to improve overall performance. The effect of isentropic efficiencies on the performance of the CCGT power plant is based on real CCGT power plants. An extensive thermodynamic analysis of the modifications of the most common configuration enhancements has been carried out. The simulation results for the HRSG configurations show that the maximum power output (1000 MW) occurred in the supplementary triplepressure reheat CCGT at high isentropic compressor efficiency. Furthermore, with the triple-pressure reheat CCGT and higher isentropic turbine efficiency the maximum overall efficiency was about $58.3 \%$. In addition, the proposed CCGT system improved the thermal efficiency by $1.6 \%$ and the power output by $11.2 \%$. Thus, the isentropic efficiencies and CCGT configurations have a strong influence on the overall performance of the CCGT.
\end{abstract}

Keywords: Combined cycle; gas-turbine; thermodynamic; isentropic efficiency.

\section{INTRODUCTION}

The GT Brayton cycle and ST Rankine cycle are compatible with each other and can be combined in such a way as to attain efficient CCGT power plants. The Brayton cycle has a high source of temperature and discards the heat at a temperature that can easily be used by the Rankine cycle plant as a source of energy. Air and steam are the most frequently used operating liquids for CCGT power plants [1]. Kaushika et al. [2] studied the best performance of a CCGT power plant, by both simulating and modelling the CCGT plant. The activities of the GT were studied and debated at part load [3]. CCGT plants represent the result of ambient temperature on sensitivity study and GT performance [4]. The optimum mixture of the parameter of procedure of steam exiting the steam generator gives the best performance of CCGT plants at part load process. The best values of the overall thermal efficiency and output of power with the values of the decision variable are demonstrated for CCGT plants [5] [6] [7]. The simulator of a 
CCGT co-generation plant was created by Khaliq and Kaushik [8], based on a computational model working on the principle of power plant modelling. This simulator comprises two sections. One deals with the simulation of the flow of fluid within the power plant, while the second shows the simulation of the regulating system of the plant [9]. Presently, the electric form of power is the most widely used worldwide. Therefore, it is imperative that the focus of the research should be on the importance of the power plants producing electric energy. Amongst the various types of power plants, thermal power plants have the highest capacity to produce energy. Many advances have taken place in the past three decades in the combined cycle (CCGT) supported gas turbine and today these are regarded as the most effective and the strongest power plants in the world [10]. As a result of this, a series of solutions were developed to accomplish the optimum structure and to improve the working of CCGT power plants. According to Mohagheghi and Shayegan [11], due to the connection of the two distinct power production cycles with the HRSG, the structure of the CCGT has become very intricate and this directly affects the power generation and thermal productivity if there is no modification in the design. CCGT plants use equipment (like gas turbines, steam turbines, compressors) whose features are standardized by the manufacturers. The components of the HRSG include an economizer, superheated steam and evaporator. The HRSG structure and the choice of the best variables are strongly influenced by the blend of the HRSG and the GT and this, in turn, strongly influences the steam cycle. Additionally, it has been suggested that the optimum variables that are associated with the steam turbine cycle may be highly affected by the performance and operating conditions of the steam turbines [12].

According to Alobaid et al. [13], the first HRSG was used in CCGT plants implementing a single pressure level. The practice of this specific solution has continued in current years, but restricted to CCGT plants of medium power output in the range of 60-70 MW and occasionally in plants generating over $100 \mathrm{MW}$. During the 1980s, the second pressure level termed as HRSG began. This introduced a new development in the industry that led at the end of the last century to the introduction of systems with three pressure levels with reheat [14]. In order to further improve the performance of the CCGT, researchers have given considerable attention to the working of the HRSG. Besides this, to enhance the overall thermal efficiency of the CCGT, the effects of a variety of factors in the design of the HRSG have been investigated. Ongiro et al. [15] studied the operation of the HRSG by developing an arithmetical technique. Dumont and Heyen [16] proposed that the once-through HRSG design is preferably harmonized to extremely elevated pressure and temperature. The authors chose a thermodynamic model and implemented it to operate with extremely elevated pressure (up to 240 bars). For investigation of the performance, a thermodynamic methodology was used for the combustion reheat GT cogeneration system through which the energetic efficiency was defined [8]. In addition to this, the effects of pinch point, steam pressure and temperature were evaluated on the thermal efficiency of the CCGT that was used in the HRSG design and reheat section. Woudstra et al. [17] provide evidence from these results that the power to heat ratio increases and thermal efficiency decreases as the temperature of the pinch point increases. When the reheat section is included, the results demonstrate a significant improvement in the heat production, power output, thermal efficiency and fuel saving [18, 19]. The thermodynamic methodology for measuring the CCGT power plant's performance is vital during the selection and comparison of combined cycle power plants [20]. A thermodynamic analysis was implemented by Atmaca [21] on the natural gas's basic cycle in combination with a 
cogeneration plant which showed that the energy usage factors and overall thermal efficiency decreased as the power to heat ratio increased. Consequently, a thermodynamic study on the effect of the isentropic compressor and turbine efficiency requires management of the effective parameters of the CCGT power plant. Thus, the aim of the present work is to develop a simulation model to enhance the performance of the CCGT power plant for several configurations, utilizing the effect of the isentropic compressor and turbine efficiency.

\section{MODELLING OF COMBINED CYCLE GAS TURBINE}

A triple-pressure reheat HRSG with a supplementary firing unit and a condensing steam turbine can be described as a complex triple-pressure CCGT plant. Three GT and three HRSG connected with one ST were associated with the unit in this model. The energy and mass balances are presented owing to the more significant and complex configuration identified with the supplementary triple-pressure reheat CCGT plant. A schematic diagram of the triple-pressure reheat combined cycle with a supplementary firing unit (TPRBCC) power plant in the midst of a simple GT cycle is depicted in Figure 1. This will produce a turbine inlet temperature of $1600 \mathrm{~K}$. The majority of the air at $\mathbf{1}$ is compressed to a higher pressure at $\mathbf{2}$. At this point, the air enters the combustion chamber [1] and undergoes combustion by utilizing additional fuel. This results in combustion gas at $\mathbf{3}$. Expansion of the gas at $\mathbf{3}$ takes place subsequently to the chimney or HRSG at $\mathbf{4}$. Heat is transferred to steam once the gas at $\mathbf{4}$ enters the HRSG, before exiting the stack temperature at 5. In the HRSG, expansion of the steam at the outlet of the high pressure superheater at $\mathbf{6}$ occurs in the high-pressure steam turbine (HPST) to a lower pressure and temperature at 7. In the reheat section, steam at $\mathbf{7}$ is reheated to a higher temperature at $\mathbf{8}$. Here, further expansion of the steam in the intermediate-pressure steam turbine (IPST) to the low pressure at $\mathbf{1 0}$ takes place. This is followed by the expansion of the superheated steam at the outlet of the intermediatepressure section of the HRSG at 9 in the intermediate-pressure steam turbine (IPST) to a lower pressure and temperature at 10, where it enters the low-pressure steam turbine. At the outlet of the low-pressure section of the HRSG at 11, the superheated steam and steam at $\mathbf{1 0}$ undergo further expansion in the low-pressure steam turbine (LPST) to low pressure and temperature at $\mathbf{1 2}$. From the low-pressure steam turbine at 2 bar, steam is extracted before being fed to the open feed water heater (deaerator) at 13. At 12, the steams with low-pressure and low-temperature will undergo condensation in the condenser and be transformed into saturated water at $\mathbf{1 4}$. The resulting water at $\mathbf{1 5}$ is the outcome of the saturated water flowing out of the condenser at $\mathbf{1 4}$ and subsequently mixing with steam at $\mathbf{1 3}$ inside the deaerating condenser. At 15, the saturated water exiting the deaerating condenser is pumped to a higher pressure at $\left(T_{w 1 L P}\right)$

. Saturated water at $\left(T_{w 2 L P}\right)$ is the result of the heating to which water at $\left(T_{w 1 L P}\right)$ is exposed in the low-pressure economizer section of the HRSG. The water then enters the low-pressure steam drum (D1). In the low-pressure superheater of the HRSG, the saturated steam at the outlet of drum D1 at $\left(T_{s L P}\right)$ is superheated. Steam at $\left(T_{s S L P}\right)$ is produced as a result. The low pressure steam turbine (LPST) becomes the recipient of the steam at $\left(T_{s s L P}\right)$, where it undergoes expansion till it enters the condenser pressure at 14. At the outlet of drum D1, the saturated water is pumped to the pressure of drum D2 at $\left(T_{w I I P}\right)$. In the intermediate-pressure economizer section of the HRSG, water at $\left(T_{w I I P}\right)$ undergoes heating till it assumes a saturated condition. Before being partly evaporated 
in the HRSG's intermediate pressure evaporation section, the saturated water at $\left(T_{w 2 I P}\right)$ undergoes heating.

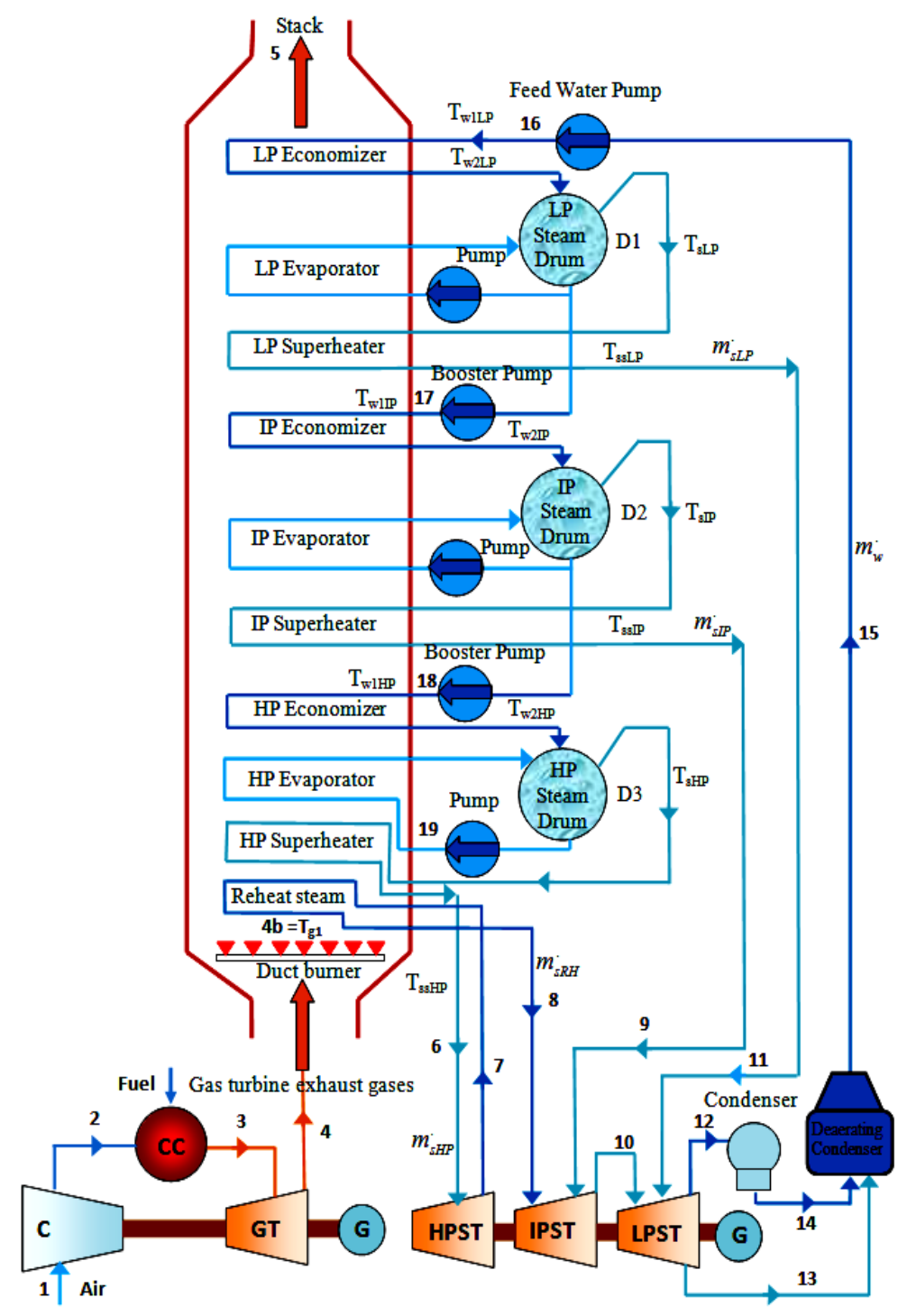

Figure 1. A schematic diagram of the supplementary firing triple-pressure steam-reheat combined cycle power plant.

At the top of drum $\mathbf{D 2}$ at $\left(T_{S I P}\right)$, the saturated vapour is superheated to a higher temperature at $\left(T_{s s I P}\right)$ in the intermediate-pressure superheater section of the HRSG. The intermediate-pressure steam turbine (IPST) becomes the recipient of the steam, where it experiences expansion until it reaches the condenser at 14. At $\left(T_{w 1 H P}\right)$, the saturated water present at the outlet of drum D2 is pumped to the pressure of drum D3. In the high-pressure economizer section of the HRSG, water at $\left(T_{w 1 H P}\right)$ undergoes heating to acquire the saturated water condition. In the high-pressure section of the HRSG, the saturated water is heated and partly evaporated. The high-pressure superheater section of the HRSG is where the saturated vapour at the top of drum D3 at $\left(T_{s H P}\right)$ is superheated to a higher temperature at $\left(T_{s s H P}\right)$. The steam expands into the reheat section at 7 after the superheated steam at $\left(T_{s S H P}\right)$ enters the high pressure steam turbine (HPST). In the reheat section of the HRSG, the steam at $\mathbf{7}$ is superheated to a higher 
temperature at $\mathbf{8}$, with some impact on the duct burner. Before being pumped to $\mathbf{1 6}$, all the steam at $\mathbf{1 2}$ will go through the process of condensation in the condenser to water at 14. The temperature transfer diagram for the CCGT power plant with a simple GT cycle is illustrated in Figure 2. The temperature-entropy diagram for the CCGT is shown in Figure 3.

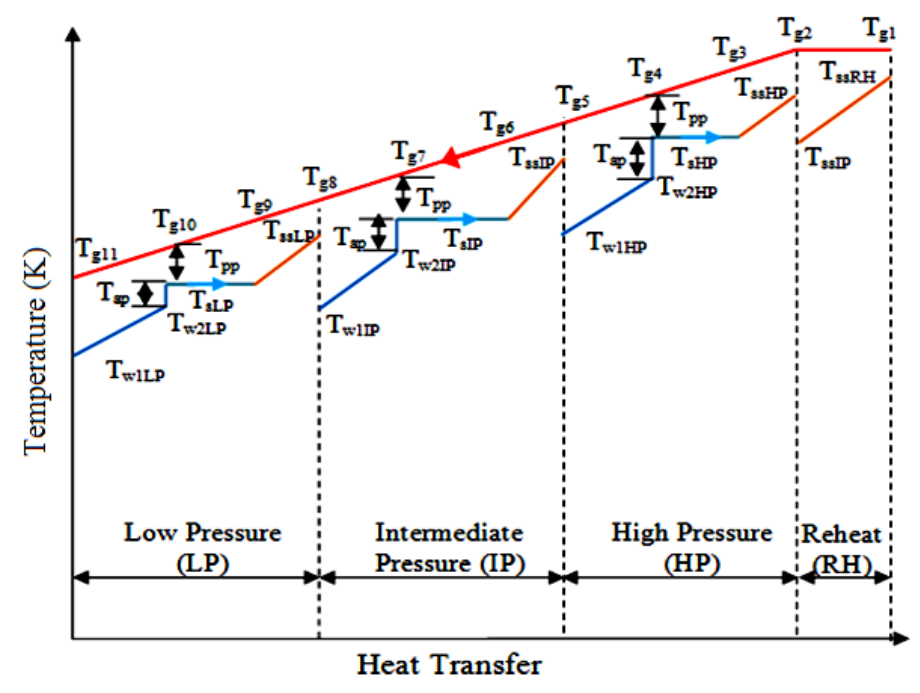

Figure 2. A typical temperature heat transfer diagram for supplementary firing of triplepressure reheat HRSG combined cycle.

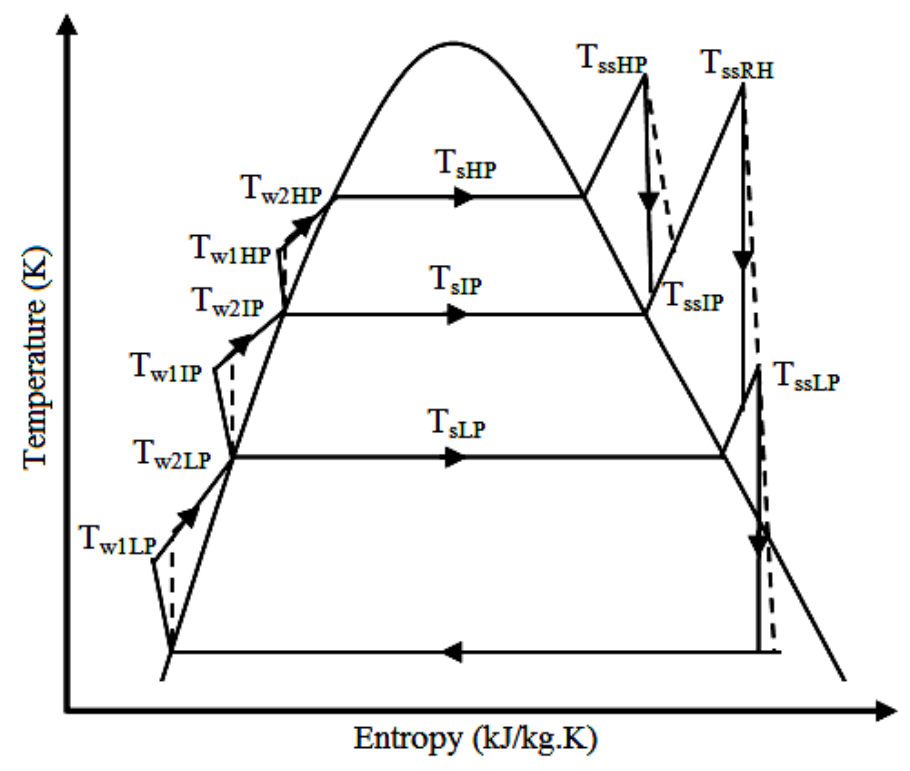

Figure 3. Temperature-entropy diagram for supplementary firing of triple-pressure reheat HRSG combined cycle.

During the analysis of the combined cycle, the following assumptions have been made [22] [23]:

1. The ambient temperature has been assumed to lie between 273 and $328 \mathrm{~K}$ while atmospheric pressure is taken as 1.01325 bar. 
2. The range of 1100 to $2000 \mathrm{~K}$ has been assumed for the turbine inlet temperature in the gas-turbine cycle.

3. The range of 75 to $100 \%$ has been taken for the isentropic efficiencies of the compressor and turbine.

4. From the combustion chamber, the heat loss is assumed to be $3 \%$ of the fuel's lower heating value $[24,25]$. Additionally, the property of being adiabatic is assumed for the rest of the components.

5. The steam cycle's maximum temperature is $873 \mathrm{~K}$.

6. The condenser pressure is assumed to be 0.07 bar

7. For the steam and gas turbine cycle, the rotational speed is assumed to be constant.

8. The pinch points in the HP, IP and LP evaporators (minimum temperature difference between the hot exhaust gases and the saturated steam) are taken as $15^{\circ} \mathrm{C}$.

9. A temperature difference of $20^{\circ} \mathrm{C}$ is assumed as the difference between the flue gas and superheated steam, i.e., the terminal temperature difference (TTD) in the HP, IP and LP.

10. A temperature difference of $60^{\circ} \mathrm{C}$ is assumed as the difference between the superheated and saturated steam, i.e., the degree of superheat (DSH) in the LP and IP.

11. The temperature difference between the steam and outlet cooling water in the condenser is assumed to be $15^{\circ} \mathrm{C}$.

12. A value of $90 \%$ is assumed for the isentropic efficiency of the steam turbine.

13. The pressure drops in the combustion chamber, HRSG and condenser are not considered.

14. No consideration is given to heat losses in the HRSG, turbines or condenser.

15. All procedures are steady state and steady flow.

16. In the combustion chamber, fuel that undergoes burning is taken as natural gas.

Equation (1) defines the compressor pressure ratio $\left(r_{p}\right)$ [26]:

$$
r_{p}=\frac{p_{2}}{p_{1}}
$$

where $p_{1}$ and $p_{2}$ denote the compressor inlet and outlet air pressure.

Equation (2) shows the calculation for the net work of the gas turbine ( $\left.W_{\text {Gnet }}\right)$ :

$$
W_{\text {Gnet }}=C_{p g} \times T I T \times \eta_{t}\left(1-\frac{1}{r_{p}^{\frac{\gamma_{g}-1}{\gamma_{g}}}}\right)-C_{p a} \times T_{1}\left(\frac{r_{p}^{\frac{\gamma_{a}-1}{\gamma_{a}}}}{\eta_{m} \eta_{c}}\right)
$$

where $\eta_{m}$ is the mechanical efficiency of the compressor and turbine, $\gamma_{a}=1.4, \gamma_{g}=1.33$, while $C_{p a}$ is the specific heat of the air and $C_{p g}$ the specific heat of the flue gas.

Equation (3) expresses the net power output of the turbine $(P)$ :

$$
P=\dot{m}_{g} \times W_{\text {Gnet }}
$$


where the mass flow rate of the exhaust gases through the gas turbine is denoted by $\dot{m}_{g}$ and Eq. (4) demonstrates this:

$$
\dot{m}_{g}=\dot{m}_{a}+\dot{m}_{f}
$$

Equation (5) below is used to determine the specific fuel consumption (SFC):

$$
S F C=\frac{3600 f}{W_{n e t}}
$$

where $(f)$ is the fuel-air ratio.

Equation (6) is another way of expressing the heat supplied:

$$
Q_{\text {add }}=C_{p g_{m}} \times\left[T I T-T_{1} \times\left(1+\frac{r_{p}^{\frac{\gamma_{a}-1}{\gamma_{a}}}-1}{\eta_{c}}\right)\right]
$$

where $L H V$ is the low heating value, $C_{p f}$ is the specific heat of the fuel, $\dot{m}_{a}$ is the air mass flow rate $(\mathrm{kg} / \mathrm{s}), T_{f}$ is the temperature of the fuel, $\dot{m}_{f}$ is the fuel mass flow rate $(\mathrm{kg} / \mathrm{s})$ and $T_{3}=T I T=$ turbine inlet temperature.

Equation (7) can now be used to calculate the GT thermal efficiency $\left(\eta_{t h}\right)$ [27] [28]:

$$
\eta_{t h}=\frac{W_{\text {Gnet }}}{Q_{\text {add }}}
$$

The following shows how the heat available with exhaust gases from the GT cycle can be presented:

$$
Q_{a v}=m_{g} \times\left(C_{p g 1} T_{g 1}-C_{p g 11} T_{g 11}\right) \times h_{1 f}
$$

The following relation has been obtained by performing the energy balance for a steam turbine:

$$
W_{s t}=m_{s H P} \times h_{6}-m_{s R H} \times h_{7}+m_{s R H} \times h_{8}+m_{s I P} \times h_{9}+m_{s L P} \times h_{7}-m_{w} \times h_{12}
$$

The water mass flow rate is denoted $m_{w}$ and calculated by using Eq. (10):

$$
m_{w}=m_{s H P}+m_{s I P}+m_{s L P}
$$

The following equation represents the heat rejected from the condenser:

$$
Q_{\text {cond }}=m_{w}\left(h_{12}-h_{14}\right)
$$

The feed pump extracts the condensate water from the condenser and raises it to the economizer pressure. Eq. (12) expresses the corresponding work of the feed water pumps for three levels:

$$
W_{p}=m_{w} \times v_{f 16}\left(p_{s h L P}-p_{c}\right)+\left(m_{w}-m_{s L P}\right) \times v_{f 17}\left(p_{s h l P}-p_{s h L P}\right)+\left(m_{w}^{-}-m_{s l P}-m_{s L P}\right) \times v_{f 18}\left(p_{s h H P}-p_{s h l P}\right)
$$

Hence, the following formula represents the net work of the steam turbine power plant:

$$
W_{\text {snet }}=W_{s t}-W_{p}
$$

The equation given below shows how calculations can be performed for the performance of the CCGT power plant, including the thermal efficiencies for the gasturbine cycle and steam-turbine cycle, and the overall efficiency [23]. The efficiency of the steam turbine power plant is: 


$$
\eta_{s t c}=\frac{W_{\text {snet }}}{Q_{a v}}
$$

The following shows the overall thermal efficiency of the CCGT power plant:

$$
\eta_{\text {all }}=\frac{3 \times W_{\text {Gnet }}+W_{\text {snet }}}{3 \times Q_{\text {add }}}
$$

\section{RESULTS AND DISCUSSION}

The trends of the exhaust temperature and steam mass flow rate of the CCGT for different configurations of HRSG with the effect of the isentropic compressor efficiency are presented in Figure 4. The effect of the isentropic compressor efficiency on the exhaust temperature of the GT and HRSG configurations is shown in Figure 4(a). It is evident that with an increase in the isentropic compressor efficiency, there is an increase in the exhaust temperature. The variations are according to the different cycle configurations. This is due to the limited values provided in the HRSG to control the exhaust temperatures $[29,30]$. The increase in the isentropic compressor efficiency was followed by a gradual decrease in the exhaust temperature of the HRSG. Lower temperatures of the exhaust gases from the HRSG are obtained in the TPRBCC configuration. As a consequence, there are higher exhaust temperatures of the HRSG in the SPCC.

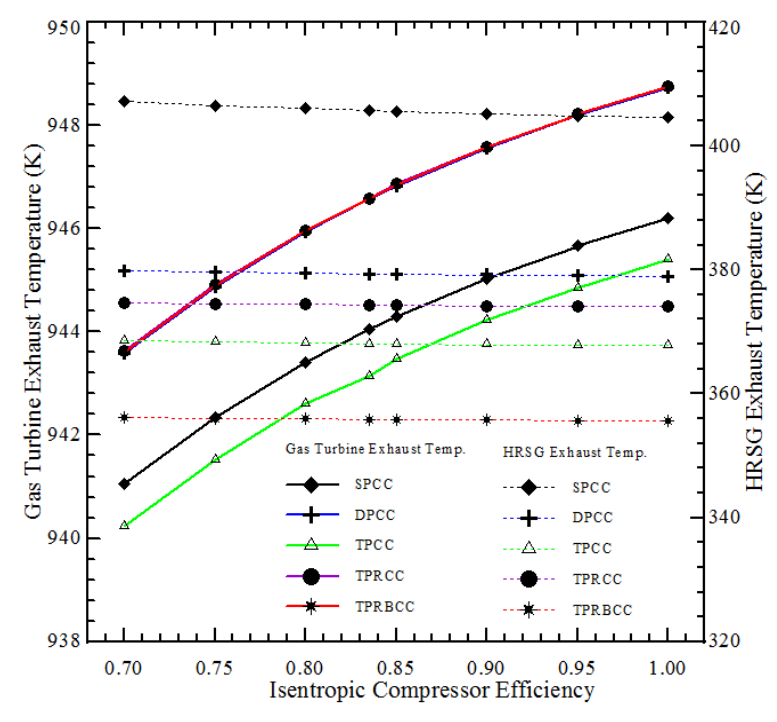

(a) Exhaust temperature

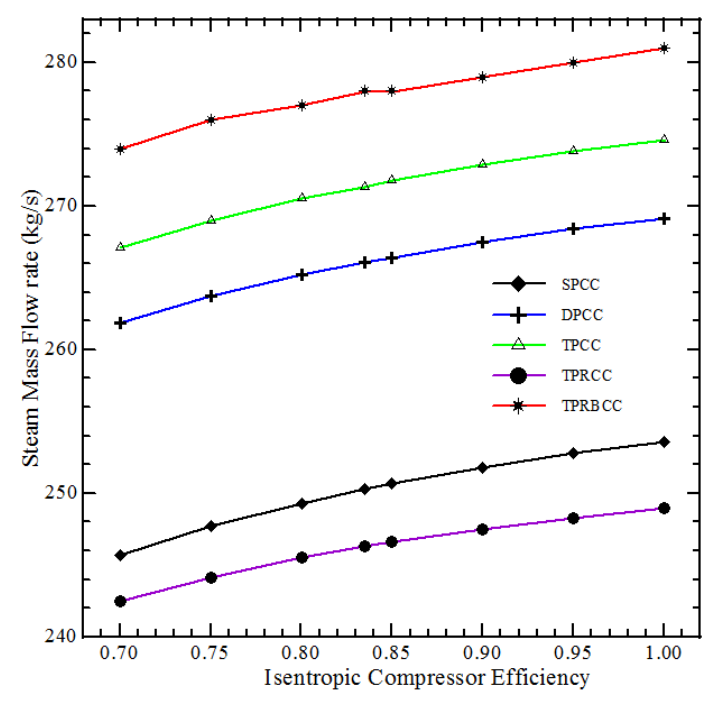

(b) Steam mass flow rate

Figure 4. Effect of the isentropic compressor efficiency on the exhaust temperature and steam mass flow rate of the CCGT for different HRSG configurations.

Figure 4(b) shows the effect of the isentropic compressor efficiency on the steam mass flow rate for different configurations of the CCGT plants. It was observed that when the isentropic compressor efficiency was increased from 70 to $100 \%$, the steam generated in the ST cycle increased by about $7.5 \mathrm{~kg} / \mathrm{s}$. As shown in Figure 4(a), this is due to the increase in the exhaust temperatures of the GT with the increase in the 
isentropic compressor efficiency. As more fuel was burnt in the HRSG, the maximum steam was produced in the TPRBCC configuration [25].

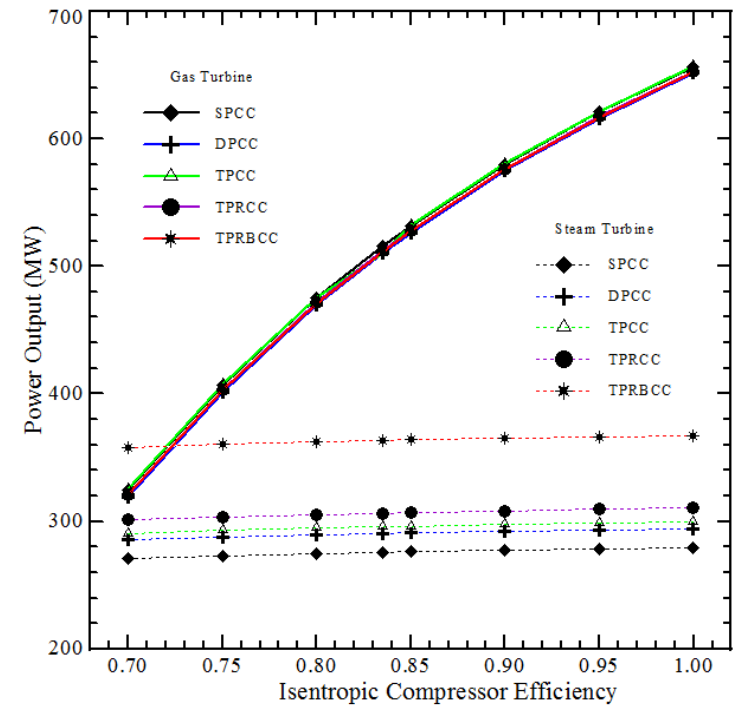

(a) Power output

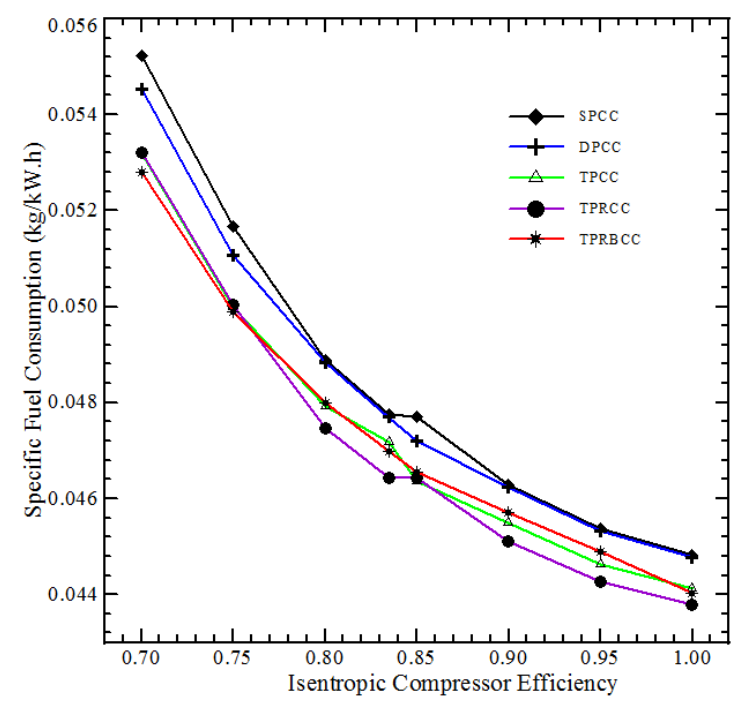

(c) Specific fuel consumption

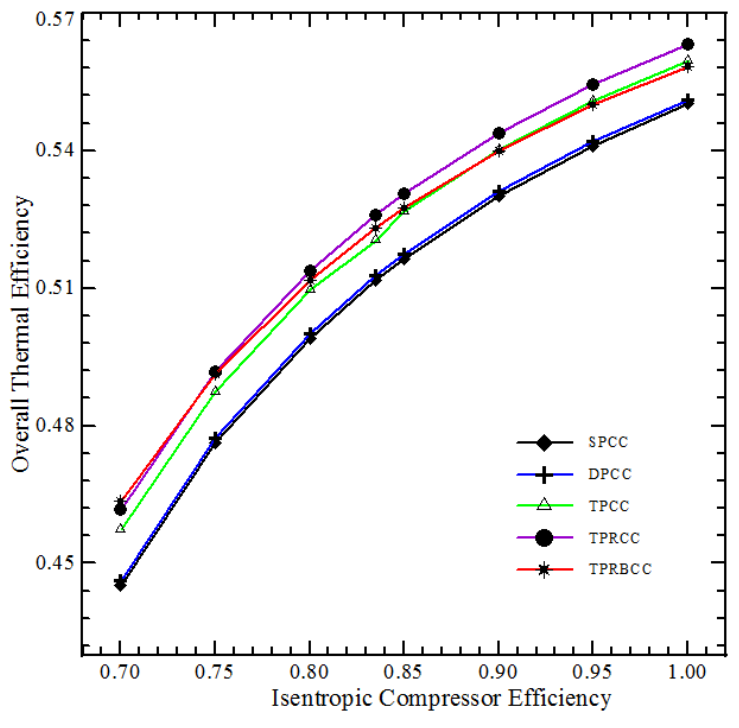

(b) Overall thermal efficiency

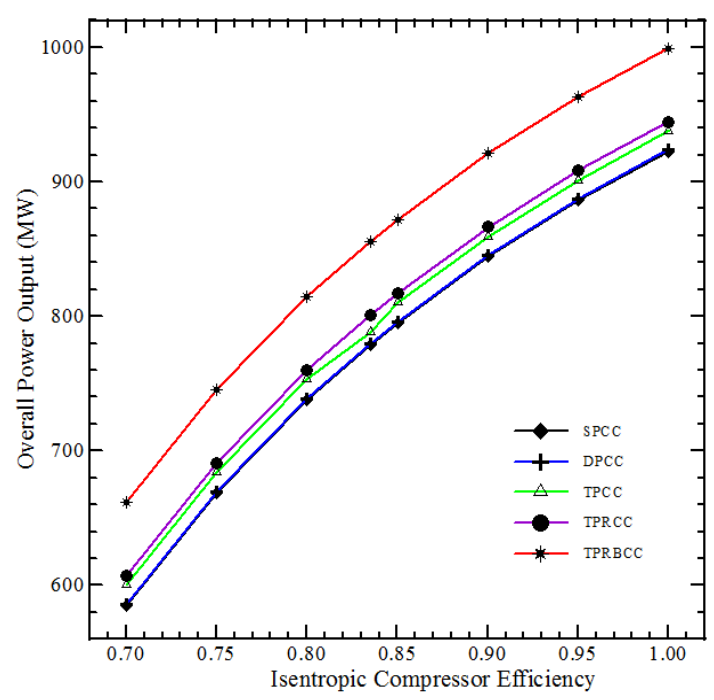

(d) Overall power output

Figure 5. Effect of the isentropic compressor efficiency on performance of different CCGT power plant configurations.

The variation of the CCGT power plant's performance for different HRSG configurations with the effect of the isentropic compressor efficiency is shown in Figure 5. The variation of the power outputs of the GT and ST with the effect of the isentropic compressor efficiency for different CCGT plant configurations is shown in Figure 5(a). When the isentropic compressor efficiency was increased from 70 to $100 \%$, the power output of the GT also increased. Normally, when the isentropic compressor efficiency increases, the losses of the air compressor are reduced, which leads to more power in the GT cycle $[31,32]$. In addition, when the isentropic compressor efficiency 
increases, the power output of the steam turbine increases very slowly. The effect of the isentropic compressor efficiency on the overall thermal efficiency of the various CCGT configurations is shown in Figure 5(b). The overall thermal efficiency for each of the configurations of the combined cycle plants increased as the isentropic compressor efficiency increased.

As shown in Figure 5(a), this was because of the increase in the power output of the GT cycle with the increase in the isentropic compressor efficiency. When the isentropic compressor efficiency increased from 70 to $100 \%$, the overall thermal efficiency increased by about $10 \%$. Similarly, the SPCC has the lowest overall thermal efficiency, while the TPRCC configuration has the highest overall thermal efficiency (about 56.2\%). The variation of the specific fuel consumption with the effect of the isentropic compressor efficiency for different CCGT plant configurations is shown in Figure 5(c). It was observed that when the isentropic compressor efficiency increased, there was a decrease in the specific fuel consumption. This is because the increase in the isentropic efficiency leads to a reduced loss in the GT [3]. When the isentropic compressor efficiency increased from 70 to $100 \%$, the lowest specific fuel consumption (from 0.0529 to $0.0438 \mathrm{~kg} / \mathrm{kWh}$ ) occurred in the TPRCC configuration, and the highest specific fuel consumption (from 0.0553 to $0.0448 \mathrm{~kg} / \mathrm{kWh}$ ) occurred in the SPCC configuration. The effect of the isentropic compressor efficiency on the overall power output for different CCGT plant configurations is shown in Figure 5(d). A high power output is obtained as a result of high isentropic compressor efficiency [3, 33, 34]. Therefore, with the increase in the isentropic compressor efficiency, the overall power output was increased for all CCGT configurations. When the isentropic compressor efficiency increased from 70 to $100 \%$, there was a $340 \mathrm{MW}$ gain in the overall power output of the CCGT, but the highest power output (from 660 to $1000 \mathrm{MW}$ ) occurred in the TPRBCC configuration and the lowest power output (from 585 to $922 \mathrm{MW}$ ) occurred in the SPCC configuration.

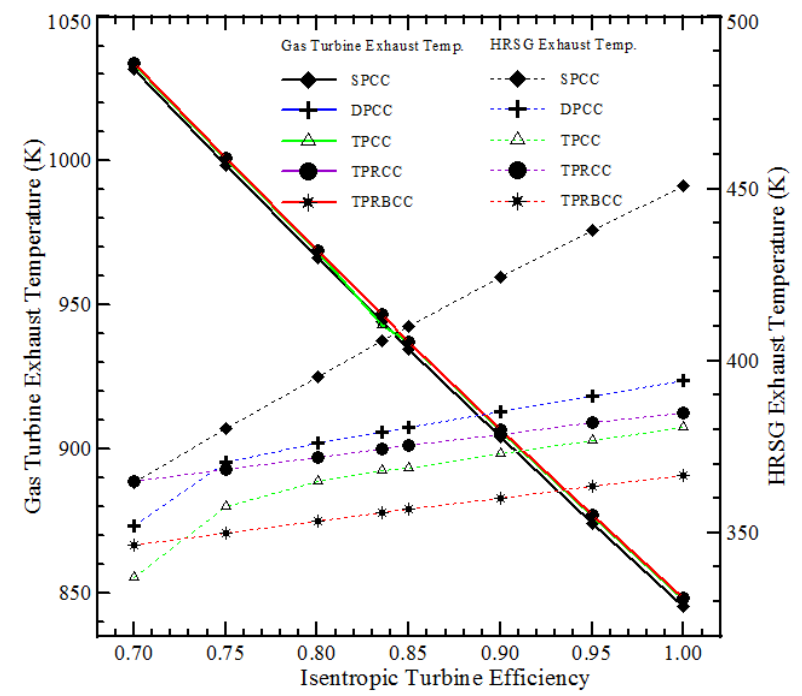

(a) Exhaust temperature

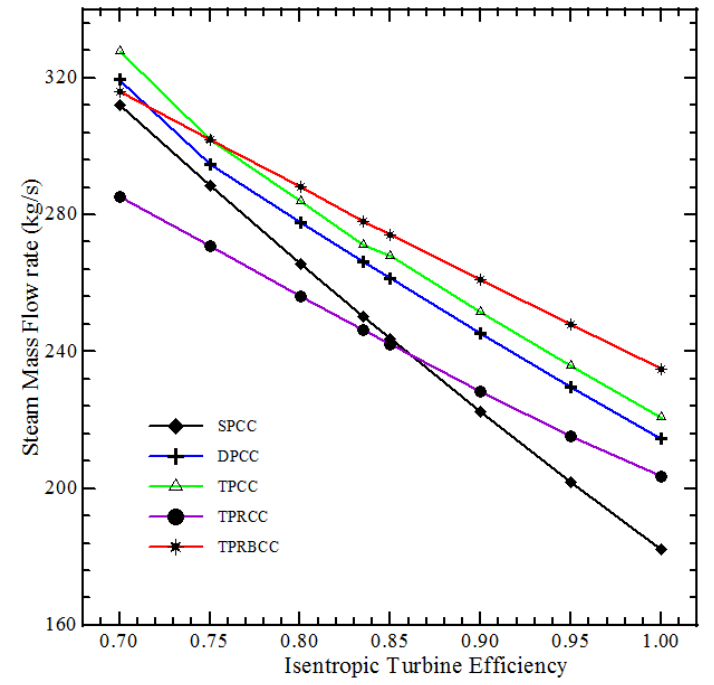

(b) Steam mass flow rate

Figure 6. Effect of the isentropic turbine efficiency on the exhaust temperature and steam mass flow rate of the CCGT for different HRSG configurations.

Figure 6 shows the effect of the isentropic turbine efficiency on the exhaust temperature and steam mass flow rate of the CCGT for different HRSG configurations. 
Figure 6(a) shows the effect of the isentropic turbine efficiency on the exhaust temperature of the GT and HRSG of the various configurations. The rise in the isentropic turbine efficiency led to a decrease in the exhaust temperature of the GT at a steeper slope. This is due to the ability of a power turbine with high isentropic efficiency to convert more energy from the hot exhaust gases [17]. The increase in the isentropic turbine efficiency leads to an increase in the exhaust temperature of the HRSG. When the isentropic turbine efficiency increased from 70 to $100 \%$, the lowest exhaust temperature (from 345 to $368 \mathrm{~K}$ ) was obtained in the TPRBCC configuration. When the isentropic turbine efficiency increased from 70 to $100 \%$, the highest exhaust temperature (from 450 to $365 \mathrm{~K}$ ) was obtained in the SPCC configuration. At lower isentropic turbine efficiency, the deviation in the exhaust temperature of the HRSG is less significant than at higher isentropic turbine efficiency. The effect of the isentropic turbine efficiency on the steam mass flow rate for different configurations of the CCGT plants is shown in Figure 6(b). Figure 6(a) shows the lower exhaust temperature obtained due to the higher isentropic turbine efficiency. Therefore, the increase in the isentropic turbine efficiency was matched with a reduced steam generation for all the configurations of the combined cycle. When the isentropic turbine efficiency was about $100 \%$, the maximum drop of the steam generated was about $218 \mathrm{~kg} / \mathrm{s}$ in the ST cycle. The greater amount of fuel burnt leads to the maximum production of steam in the TPRBCC configuration. On the other hand, in the SPCC configuration the minimum steam is produced.

Figure 7 shows the variation of performance of different configurations of the CCGT power plants with the effect of the isentropic turbine efficiency. The variation of the simulated power outputs of the GT and ST configurations with the effect of the isentropic turbine efficiency is shown in Figure 7(a). There is an increase in the power output of the GT with the increase in the isentropic turbine efficiency at given values of temperature, pressure and pressure ratio. To increase the component efficiencies, the power output plays a very important role. When the isentropic turbine efficiency increased from 70 to $100 \%$, the GT power output also increased, from 370 to $678 \mathrm{MW}$. In addition, the increase in the isentropic turbine efficiency leads to a decrease in the power output of the ST cycle. Figure 7(b) shows the reduced steam generated by the HRSG due to the reduced exhaust temperature of the GT under the effect of the increased isentropic turbine efficiency. However, the increase in the isentropic turbine efficiency from 70 to $100 \%$ led to a decrease in the power output by $142 \mathrm{MW}$ for the ST cycle. When the isentropic turbine efficiency was increased from 70 to $100 \%$, the peak power output was obtained and reduced from 417 to $296 \mathrm{MW}$. The behaviour of the overall thermal efficiency with isentropic turbine efficiency variations for the different configurations of the combined cycle is shown in Figure 7(b). The increase in the isentropic thermal efficiencies for the various configurations leads to a steep rise in the overall thermal efficiency. As shown in Figure 7(a), the increased power of the GT, more than the decreased power of ST, was the main reason for this. In addition, the increase of the overall thermal efficiency was due to the reduction in the exhaust temperature of the GT. When the isentropic turbine efficiency increased from 70 to $100 \%$, there was an increase in the overall peak thermal efficiency from 47.6 to $58.2 \%$ in the TPRCC configuration, and the lowest overall thermal efficiency from 46.2 to $56.5 \%$ was obtained in the SPCC configuration. 


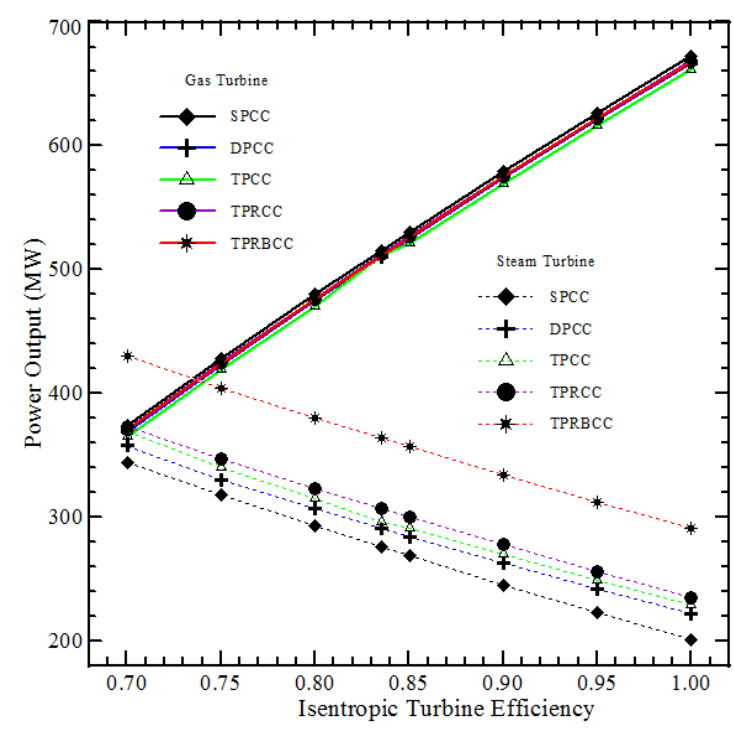

(a) Power output

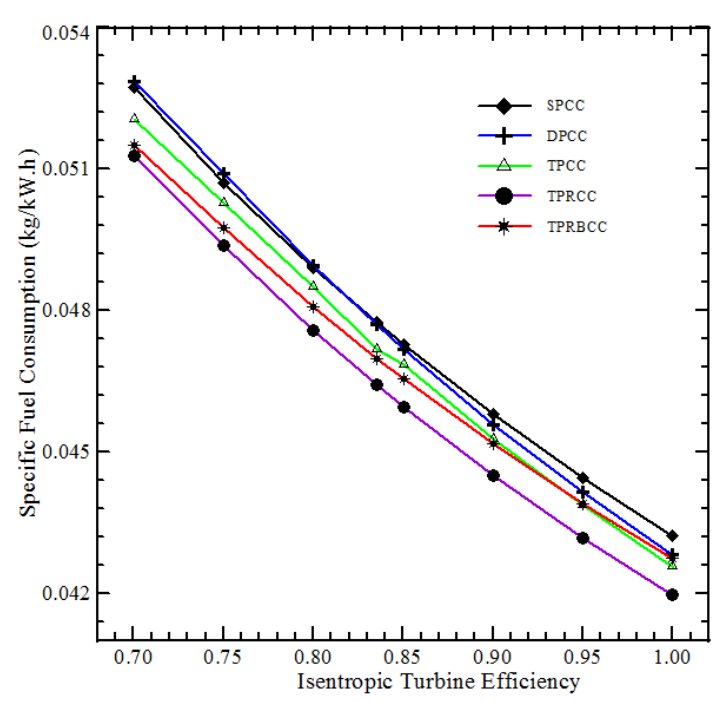

(c) Specific fuel consumption

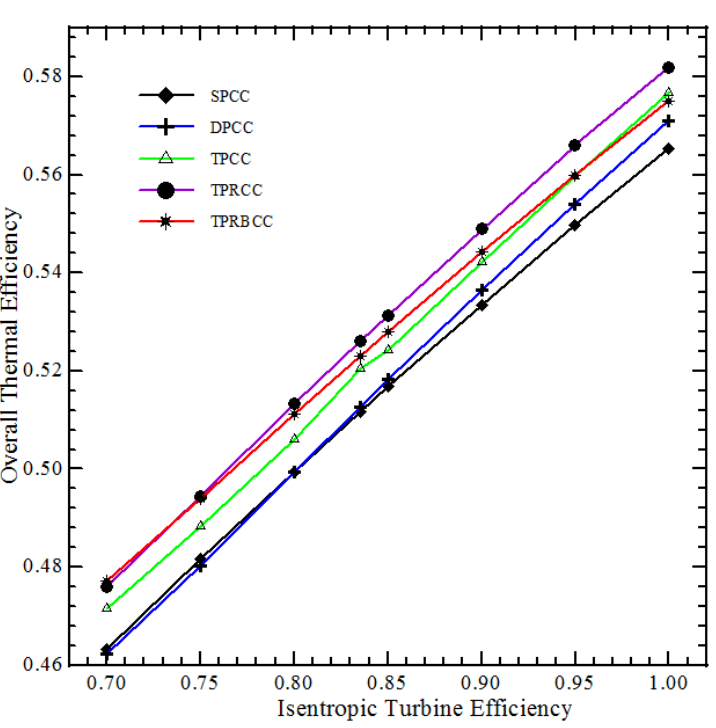

(b) Overall thermal efficiency

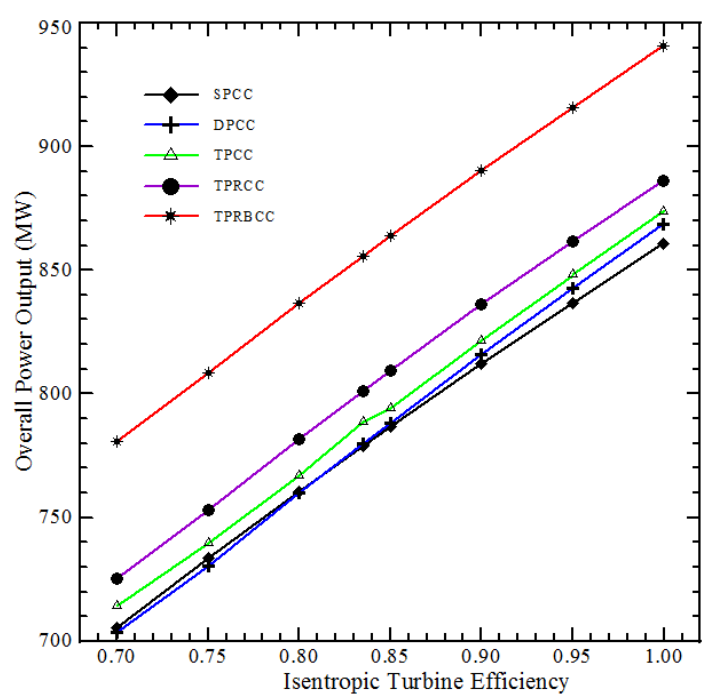

(d) Overall power output

Figure 7. Effect of the isentropic turbine efficiency on performance of different configurations of the CCGT power plants.

Figure 7(c) shows the trends of the specific fuel consumption with the effect of variation of the isentropic turbine efficiency. The result was a steeper decline as the isentropic turbine efficiency increased. In addition, there was a decrease in the losses and the exhaust temperature with increase in the isentropic turbine efficiency. This led to decrease in the burnt fuel $[19,35]$. For this reason, the specific fuel consumption decreased with increase of the isentropic turbine efficiency. When the isentropic turbine efficiency increased from 70 to $100 \%$, the best specific fuel consumption $(0.0513$ to $0.042 \mathrm{~kg} / \mathrm{kWh}$ ) occurred in the TPRCC configuration. When the isentropic turbine efficiency increased from 70 to $100 \%$ in the SPCC configuration, the highest specific fuel consumption ( 0.0528 to $0.0432 \mathrm{~kg} / \mathrm{kWh})$ occurred. The effect of the isentropic turbine efficiency on the overall power outputs for different configurations of CCGT 
plants is shown in Figure 7(d). The network obtained is high due to the higher isentropic turbine efficiency from the GT, which leads to a reduction in the heat losses $[8,26]$. For these reasons, there was a linear increase in the isentropic turbine efficiency with the increase in the overall power output for all the configurations. When the isentropic turbine efficiency increased from 70 to $100 \%$ in the CCGT, the overall power output increased by about $170 \mathrm{MW}$, the lowest power output (702 to $861 \mathrm{MW}$ ) occurred in the SPCC configuration and the highest power output (780 to $942 \mathrm{MW}$ ) occurred in the TPRBCC configuration.

\section{CONCLUSIONS}

In this paper, an attempt was made to develop a simulation model for several configurations of the CCGT cycle and these were assessed with the influence of the isentropic compressor and turbine efficiency. The performance codes were developed based on MATLAB code. To obtain the maximum thermal efficiency and power generation, multi-configured parameters were designed. Parametrical analysis was performed to investigate the performance of CCGT plants, using as parameters the isentropic compressor and turbine efficiency of the GT. Furthermore, the highest thermal efficiency occurred in the TPRCC configuration while the maximum power output was recorded for the TPRBCC configuration.

\section{ACKNOWLEDGEMENTS}

The authors would like to be obliged to Universiti Malaysia Pahang for providing laboratory facilities and financial assistance under project No. GRS100332.

\section{REFERENCES}

[1] Micheli D, Pinamonti P, Reini M, Taccani R. Performance analysis and working fluid optimization of a cogenerative organic rankine cycle plant. Journal of Energy Resources Technology. 2013;135:021601.

[2] Kaushik S, Reddy VS, Tyagi S. Energy and exergy analyses of thermal power plants: A review. Renewable and Sustainable Energy Reviews. 2011;15:185772.

[3] Haglind F. Variable geometry gas turbines for improving the part-load performance of marine combined cycles-Combined cycle performance. Applied Thermal Engineering. 2011;31:467-76.

[4] Srinivas T, Gupta A, Reddy B. Thermodynamic modeling and optimization of multipressure heat recovery steam generator in combined power cycle. Journal of Scientific and Industrial Research. 2008;67:827-34.

[5] Ibrahim TK, Rahman M, Alla ANA. Study onthe effective parameter of gas turbine model with intercooled compression process. Scientific Research and Essays. 2010;5:3760-70.

[6] Ibrahim TK, Rahman M, Abdalla AN. Gas turbine configuration for improving the performance of combined cycle power plant. Procedia Engineering. 2011;15:4216-23.

[7] Ibrahim TK, Rahman M, Abdalla AN. Improvement of gas turbine performance based on inlet air cooling systems: A technical review. International Journal of Physical Sciences. 2011;6:620-7. 
[8] Khaliq A, Kaushik S. Thermodynamic performance evaluation of combustion gas turbine cogeneration system with reheat. Applied Thermal Engineering. 2004;24:1785-95.

[9] Khosravi-el-Hossani M, Dorosti Q. Improvement of gas turbine performance test in combine-cycle. WASET. 2009;34:383-6.

[10] Ghazi M, Ahmadi P, Sotoodeh A, Taherkhani A. Modeling and thermoeconomic optimization of heat recovery heat exchangers using a multimodal genetic algorithm. Energy Conversion and Management. 2012;58:149-56.

[11] Mohagheghi M, Shayegan J. Thermodynamic optimization of design variables and heat exchangers layout in HRSGs for CCGT, using genetic algorithm. Applied Thermal Engineering. 2009;29:290-9.

[12] Ibrahim TK, Rahman M. Effective Parameters on performance of multipressure combined cycle power plants. Advances in Mechanical Engineering. 2014;6:781503.

[13] Alobaid F, Ströhle J, Epple B, Kim H-G. Dynamic simulation of a supercritical once-through heat recovery steam generator during load changes and start-up procedures. Applied Energy. 2009;86:1274-82.

[14] Jericha H, Fesharaki M, Seyr A. Multiple evaporation steam bottoming cycle. ASME 1997 International Gas Turbine and Aeroengine Congress and Exhibition: American Society of Mechanical Engineers; 1997. p. V002T08A6VT08A6.

[15] Ong'Iro A, Ugursal V, Al Taweel A, Walker J. Modeling of heat recovery steam generator performance. Applied Thermal Engineering. 1997;17:427-46.

[16] Dumont M-N, Heyen G. Mathematical modelling and design of an advanced once-through heat recovery steam generator. Computers \& chemical engineering. 2004;28:651-60.

[17] Woudstra N, Woudstra T, Pirone A, Van Der Stelt T. Thermodynamic evaluation of combined cycle plants. Energy Conversion and Management. 2010;51:1099-110.

[18] Carcasci C, Costanzi F, Pacifici B. Performance analysis in off-design condition of gas turbine air-bottoming combined system. Energy Procedia. 2014;45:103746.

[19] Basha M, Shaahid S, Al-Hadhrami L. Impact of fuels on performance and efficiency of gas turbine power plants. Energy Procedia. 2012;14:558-65.

[20] Gyftopoulos EP. Energy conservation education: Major considerations. Journal of Energy Resources Technology. 2015;137:021002.

[21] Atmaca M. Efficiency analysis of combined cogeneration systems with steam and gas turbines. Energy Sources, Part A: Recovery, Utilization, and Environmental Effects. 2010;33:360-9.

[22] Ibrahim TK, Rahman M. Optimum performance improvements of the combined cycle based on an intercooler-reheated gas turbine. Journal of Energy Resources Technology. 2015;137:061601.

[23] Ibrahim TK, Rahman MM. Effect of Compression Ratio on the Performance of Different Strategies for the Gas Turbine. International Journal of Automotive and Mechanical Engineering. 2014;9:1747-57.

[24] Ibrahim TK, Rahman M. Parametric simulation of triple-pressure reheat combined cycle: A case study. Advanced Science Letters. 2012;13:263-8.

[25] Ibrahim TK, Rahman MM. Study on effective parameter of the triple-pressure reheat combined cycle performance. Thermal Science. 2013;17:497-508. 
[26] Ibrahim TK, Rahman M. Effect of compression ratio on the performance of different strategies for the gas turbine. International Journal of Automotive and Mechanical Engineering (IJAME). 2014;9:1747-57.

[27] Rahman M, Ibrahim TK, Taib M, Noor M, Bakar RA. Thermal analysis of opencycle regenerator gas-turbine power-plant. World Academy of Science, Engineering and Technology.4:1084-9.

[28] Rahman M, Ibrahim TK, Kadirgama K, Mamat R, Bakar RA. Influence of operation conditions and ambient temperature on performance of gas turbine power plant. Advanced Materials Research. 2011;189:3007-13.

[29] Sindareh-Esfahani P, Ghaffari A, Ahmadi P. Thermodynamic modeling based optimization for thermal systems in heat recovery steam generator during cold start-up operation. Applied Thermal Engineering. 2014;69:286-96.

[30] Bassily A. Analysis and cost optimization of the triple-pressure steam-reheat gas-reheat gas-recuperated combined power cycle. International Journal of Energy Research. 2008;32:116-34.

[31] Ibrahim TK, Rahman M, Sharma K. Influence of operation conditions on performance of combined cycle gas turbine. ASME 3rd International Conference on Mechanical and Electrical Technology2011. p. 1-8.

[32] Rahman M, Ibrahim TK, Abdalla AN. Thermodynamic performance analysis of gas-turbine power-plant. International Journal of the Physical Sciences. 2011;6:3539-50.

[33] Han W, Chen Q, Lin R-m, Jin H-g. Assessment of off-design performance of a small-scale combined cooling and power system using an alternative operating strategy for gas turbine. Applied Energy. 2015;138:160-8.

[34] Sanjay Y, Singh O, Prasad B. Energy and exergy analysis of steam cooled reheat gas-steam combined cycle. Applied Thermal Engineering. 2007;27:2779-90.

[35] Dechamps P. Advanced combined cycle alternatives with the latest gas turbines. ASME 1996 Turbo Asia Conference: American Society of Mechanical Engineers; 1996. p. V001T04A6-VT04A6. 